\title{
Antioxidant Properties and Total Phenolic Content of Eight Salvia Species from Turkey
}

\author{
MURAT TOSUN ${ }^{1}$ SEZAI ERCISLI ${ }^{2}$ MEMNUNE SENGUL ${ }^{3}$ HAKAN OZER $^{4}$ \\ TASKIN POLAT ${ }^{4}$ and ERDOGAN OZTURK ${ }^{4}$ \\ ${ }^{1}$ Ataturk University Oltu Vocational School, 25800 Oltu, Erzurum-Turkey. \\ ${ }^{2}$ Ataturk University Agricultural Faculty Department of Horticulture, 25240 Erzurum-Turkey. \\ ${ }^{3}$ Ataturk University Agricultural Faculty Department of Food Science 25240 Erzurum-Turkey. \\ ${ }^{4}$ Ataturk University Agricultural Faculty Department of Field Crops, 25240 Erzurum-Turkey.
}

\begin{abstract}
Methanolic extracts of eight Salvia species, namely S. aethiopis, S. candidissima, S. limbata, S. microstegia, S. nemorosa, $S$. pachystachys, $S$. verticillata, and $S$. virgata, sampled from Eastern Anatolia in Turkey, were screened for their possible antioxidant activities by two complementary test systems, namely DPPH free radical scavenging and $\beta$-carotene/linoleic acid. Total phenolic content of the extracts of Salvia species were performed Folin-Ciocalteu reagent and gallic acid used as standard. A wide variation has been observed among species in terms of antioxidant activity and total phenolic content. In both DPPH and $\beta$-carotene system, the most active plant was Salvia verticillata with a value of $I C_{50}=18.3 \mu \mathrm{g} / \mathrm{ml}$ and $75.8 \%$, respectively. This specie also has the highest total phenolic content (167.1 mgGAE/g DW). The total amount of phenolics was between 50.3 to $167.1 \mathrm{mg} \mathrm{GAE} / \mathrm{g}$ DW among species. A positive linear correlation was observed between total phenolic content and antioxidant activity of the extracts. The results suggest that the extract of Salvia species, notably Salvia verticillata with the highest antioxidant activity, can be used as natural antioxidants in the food industry.
\end{abstract}

Key terms: DPPH, Sage, Salvia, total phenolic content.

\section{INTRODUCTION}

The human body produces reactive oxygen species (ROS), such as superoxide anion radical, hydroxyl radical and hydrogen peroxide, by many enzymatic systems through oxygen consumption. In small amounts, these ROS can be beneficial as signal transducers (1) and growth regulators (2). However, during oxidative stress, large amounts of these ROS can be produced and may be dangerous because of their ability to attack numerous molecules, including proteins and lipids (3). In fact, it has been reported that ROS largely contribute to cellular aging (4), mutagenesis (5), and coronary heart disease (6) through several ways, including membrane destabilisation (7), DNA breakage (5) and generally by oxidising low-density lipoproteins (LDL).
The cell can reduce the impact of ROS either by an endogenous system implicating enzymes such as catalase and superoxide dismutase or by an exogenous system using antioxidants, vitamin $\mathrm{C}$ and a-tocopherol (8).

In recent years, plant extracts have appeared on the market as antioxidants for food industry use. The antioxidant capacity of some of these compounds has been proved to be comparable to, and sometimes higher than, that of synthetic antioxidants $(9,10)$. In particular, the Lamiaceae family includes a large number of plants that are well known for their antioxidant properties. Among these, sage has been widely used and most of its antioxidant components have been identified. It has been established that the antioxidant effects of sage are mainly due to phenolic compounds $(10,11$, 12). 
The genus Salvia (Lamiaceae) includes nearly 900 species spread throughout the world. This genus is represented in Turkey by 89 species and, altogether, 94 taxa, 45 of which are endemic in Turkey. The rate of endemism in the genus Salvia in Turkey is ca. $45 \%$ (13). Many Salvia species are used as herbal tea and for food flavouring, as well as in cosmetics, perfumery and the pharmaceutical industries throughout world (14).

The aim of the present study was to examine the in vitro antioxidant activities of the methanolic extracts of eight Salvia species. A literature survey did not reveal any reference to any previous work comparing the antioxidant activities of these species. Most of the studies in the literature are focused on Salvia officinalis (garden sage), since it is used as a reference plant because of its well-known and widely documented antioxidant properties. Therefore, we think that the results presented here will provide new information on the species studied.

\section{MATERIALS AND METHODS}

\section{Chemicals}

All the chemicals used were purchased from Sigma \& Aldrich company and were of analytical grade.

\section{Plant material}

The plant material (aerial parts) was collected in mid-July of 2007 from the Erzurum Region in eastern Turkey. All plant materials were authenticated by Dr. Meryem Sengul of the Department of Biology of Ataturk University. The voucher specimens have been deposited at the Herbarium of the Department of Field Crops of the Agricultural Faculty of Ataturk University, Erzurum-Turkey.

\section{Preparation of the methanolic extracts}

The air-dried and finely ground samples (weighing about $100 \mathrm{~g}$ ) were extracted in a Soxhlet with methanol $(\mathrm{MeOH})$ at $60^{\circ} \mathrm{C}$ for
$6 \mathrm{~h}$. The samples were then lyophilized and kept in the dark at $+4{ }^{0} \mathrm{C}$ until tested.

\section{Assay for total phenolics}

Total phenolic constituents of Salvia extracts were performed employing methods from the literature involving Folin-Ciocalteu reagent and used gallic acid as standard (15).

\section{DPPH assay}

The hydrogen atom or electron donation abilities of the corresponding extracts and some pure compounds were measured from the bleaching of the purple-colored methanol solution of DPPH. This spectrophotometer assay uses the stable radical, 2,2' diphenylpicrylhydrazyl (DPPH·), as a reagent (16). $50 \mu \mathrm{l}$ of various concentrations of the extracts in methanol were added to 5 $\mathrm{ml}$ of a $0.004 \%$ methanol solution of DPPH. After a $30 \mathrm{~min}$ incubation period at room temperature, the absorbance was read against a blank at $517 \mathrm{~nm}$. Inhibition of free radical DPPH in percent $(1 \%)$ was calculated in following way: $I \%=\left(A_{\text {blank }}-A_{\text {sample }} / A_{\text {blank }}\right)$ x 100 ; where $A_{\text {blank }}$ is the absorbance of the control reaction (containing all reagents except the test compound), and $A_{\text {sample }}$ is the absorbance of the test compound. Extract concentration providing $50 \%$ inhibition $\left(I C_{50}\right)$ was calculated from the graph plotting inhibition percentage against extract concentration. Tests were carried out in triplicate.

\section{$\beta$-Carotene/linoleic acid assay}

In this assay, antioxidant capacity is determined by measuring the inhibition of the volatile organic compounds and the conjugated diene hydroperoxides arising from linoleic acid oxidation (17). A stock solution of $\beta$-carotene/linoleic acid mixture was prepared as follows: $0.5 \mathrm{mg} \beta$-carotene was dissolved in $1 \mathrm{ml}$ of chloroform (HPLC grade), and $25 \mu \mathrm{l}$ linoleic acid and $200 \mathrm{mg}$ Tween 40 were added. Chloroform was completely evaporated using a vacuum evaporator. Then, $100 \mathrm{ml}$ distilled water, saturated with oxygen $(30 \mathrm{~min} 100 \mathrm{ml} / \mathrm{min})$, 
was added with vigorous shaking; $2.5 \mathrm{ml}$ of this reaction mixture was dispersed into test tubes and $350 \mu \mathrm{l}$ portions of the extracts prepared at $2 \mathrm{~g} / \mathrm{l}$ concentrations were added and the emulsion system was incubated for $48 \mathrm{~h}$ at room temperature. The same procedure was repeated with the synthetic antioxidant BHA as a positive control and with a blank. After the incubation period, absorbances of the mixtures were measured at $490 \mathrm{~nm}$. Antioxidative capacities of the extracts were compared with those of BHA and the blank.

\section{RESULTS AND DISCUSSION}

Total phenolic content and in vitro antioxidant activities by using DPPH and $\beta$ Carotene/linoleic acid assay of methanolic extract from S. aethiopis, S. candidissima, $S$. limbata, S. microstegia, S. nemorosa, $S$. pachystachys, S. verticillata, and $S$. virgata were investigated and results are shown below.

\section{Total phenolic content}

Based on the absorbance values of the various extract solutions, reacted with Folin-Ciocalteu reagent and compared with the standard solutions of gallic acid equivalents as described by Slinkard and Singleton (15), results of the colorimetric analysis of total phenolics are given in Table 1.

The amount of the total phenolics was highest in Salvia verticillata (167.1 mgGAE/g DW), followed by Salvia virgata (101.2 mgGAE/g DW) and Salvia candidissima (100.3 mgGAE/g DW). Salvia microstegia had the lowest total phenolic content (50.3 mgGAE/g DW). As far as our literature survey could ascertain, several studies have been carried out with the Salvia species and total phenolic content has been found to be between 41-134 $\mathrm{mgGAE} / \mathrm{g}$ DW basis $(18,19)$. All these results support our findings.

\section{Free-radical scavenging capacity (DPPH)}

The free radical scavenging activities of the obtained extracts from eight Salvia species are given in Table 1. As can be seen in Table 1, there were statistically important differences among Salvia species in terms of free-radical scavenging capacity. $I C_{50}$ is the amount of extracts providing $50 \%$ inhibition of hydroxyl radicals and values lower than $I C_{50}$ reflect better protective action of the extracts.

TABLE 1

Free radical-scavenging capacities and the inhibition ratio of linoleic acid oxidation by extracts measured in DPPH and $\beta \leq$-carotene/linoleic acid assays of eight Salvia species

\begin{tabular}{lccc}
\hline Species & $\begin{array}{c}\text { Antioxidant activity (DPPH } \\
\text { 2,2-diphenylpicrylhydrazyl assay) }\end{array}$ & $\begin{array}{c}\text { Antioxidant activity } \\
(\beta \leq- \text {-carotene/linoleic acid assay) }\end{array}$ & $\begin{array}{c}\text { Total phenolic content } \\
(\mathrm{mg} \text { GAE/g DW) }\end{array}$ \\
\hline S. aethiopis & $34.0 \mathrm{~d}$ & $70.4 \mathrm{bc}$ & $82.1 \mathrm{e}$ \\
S. candidissima & $33.4 \mathrm{de}$ & $69.8 \mathrm{c}$ & $87.1 \mathrm{de}$ \\
S. limbata & $88.2 \mathrm{a}$ & $75.8 \mathrm{~b}$ & $167.1 \mathrm{a}$ \\
S. microstegia & $64.3 \mathrm{~b}$ & $73.8 \mathrm{bc}$ & $92.1 \mathrm{~cd}$ \\
S. nemorosa & $32.0 \mathrm{e}$ & $68.6 \mathrm{~cd}$ & $63.9 \mathrm{f}$ \\
S. pachystachys & $51.0 \mathrm{c}$ & $73.2 \mathrm{bc}$ & $100.3 \mathrm{bc}$ \\
S. verticillata & $18.3 \mathrm{~g}$ & $62.5 \mathrm{~d}$ & $50.3 \mathrm{~g}$ \\
S. virgata & $23.4 \mathrm{f}$ & $69.4 \mathrm{c}$ & $101.2 \mathrm{~b}$ \\
BHA & $15.2 \mathrm{~g}$ & $98.3 \mathrm{a}$ & \\
Mean & 42.6 & 70.4 & 93.0 \\
LSD & 1.6 & 3.8 & 8.2 \\
\hline
\end{tabular}

* Values in the same column with different lower-case letters are significantly different at $P<0.05$. 
The best $I C_{50}$ values were obtained from Salvia verticillata as $18.3 \mu \mathrm{g} / \mathrm{ml}$. The other species that have high free radicalscavenging capacity were Salvia virgata $(23.4 \mu \mathrm{g} / \mathrm{ml})$ and Salvia nemorosa $(32.0 \mu \mathrm{g} /$ $\mathrm{ml}$ ), respectively. The control (BHA) had the lowest radical-scavenging capacity (15.2 $\mu \mathrm{g} / \mathrm{ml}$ ) of all Salvia species, but statistically within the same group with Salvia virgata $(23.4 \mu \mathrm{g} / \mathrm{ml})$ (Table 1). Previously, radical scavenging capacity of Salvia species were found to be between $18.00-81.00 \mu \mathrm{g} / \mathrm{ml}$ in Turkey $(19,20,21)$ and $23.53-125.10 \mu \mathrm{g} / \mathrm{ml}$ in Iran (22). All these findings are in accordance with our results. Hydroxyl radical is a biologically relevant and extremely reactive oxygen species, which can rapidly react and degrade with susceptible food and biologically relevant substrates, such as polyunsaturated fatty acids, proteins, carbohydrates and DNA (3). DPPH is a stable free radical and accepts the hydrogen radical to become a stable diamagnetic molecule, yellow coloured diphenylpicrylhydrazine (23). The synthetic nitrogen-centred DPPH is not biologically relevant, but is often used as an indicator compound in testing of hydrogen-donation capacity and thus antioxidant activity.

\section{Antioxidant activity ( $\beta$-Carotene/Linoleic Acid Assay)}

Table 1 shows the antioxidant activity of the 8 Salvia species extracts as measured by the bleaching of $\beta$-Carotene. In $\beta$-Carotene/ linoleic acid assay, oxidation of linoleic acid was effectively inhibited by Salvia verticillata extract $(75.8 \%)$, followed by Salvia virgata $(73.8 \%)$ and Salvia nemorosa (73.2\%), respectively (Table 1). The antioxidant activity of synthetic BHA was $98.3 \%$ indicating higher values than all Salvia species. Antioxidant activity using $\beta$-Carotene/linoleic acid assay of Salvia species has previously been studied and the antioxidant activity were between 29.0 and $69.2 \%(18,20)$.

$\beta$-Carotene undergoes rapid discoloration in the absence of an antioxidant. This is because of the coupled oxidation of $\beta$ Carotene and linoleic acid, which generates free radicals. The linoleic acid free radical formed upon the abstraction of a hydrogen atom from one of its diallylic methylene groups, attacks the highly unsaturated $\beta$ Carotene molecules. As a result, $\beta$-Carotene will be oxidized and broken down in part. Subsequently, the system looses its chromophore and characteristic orange colour, which can be monitored spectrophotometrically. The presence of different antioxidants can hinder $\beta$-Carotene bleaching by neutralizing the linoleic-free radical and other free radicals formed in the system (24).

\section{Relationships between antioxidant activity and total phenolic content}

It is extremely important to point out that there is a positive correlation between antioxidant activity and the total phenolic content of the extracts (Figure 1). Phenols are very important plant constituents because of their scavenging ability on free radicals due to their hydroxyl groups (25). Therefore, the phenolic content of plants may contribute directly to their antioxidant action. Plants belonging to the Lamiaceae family are very rich in polyphenolic compounds. The major phenolic compounds identified in the extracts of sage are rosmarinic acid, carnosic acid, salvianolic acid and its derivates carnosol, rosmanol, epirosmanol, rosmadial and methyl carnosate $(26,27,28)$. Among these, rosmanol is a major constituent of many Salvia species and has strong antioxidant activities because these groups cause phenols to more easily donate hydrogen atoms to activate free radicals to interrupt the chain reaction of antioxidation (29). The DPPH scavenging capacity of these extracts may be mostly related to their phenolic hydroxyl groups. However, these properties of putative antioxidants have been attributed to various mechanisms, among which are prevention of radical chain initiation, binding of transition metal ions catalysts, decomposition of peroxides, prevention of continued hydrogen abstraction and radical scavenging (30).

According to the above, all results were wide diverse on antioxidant activity and 

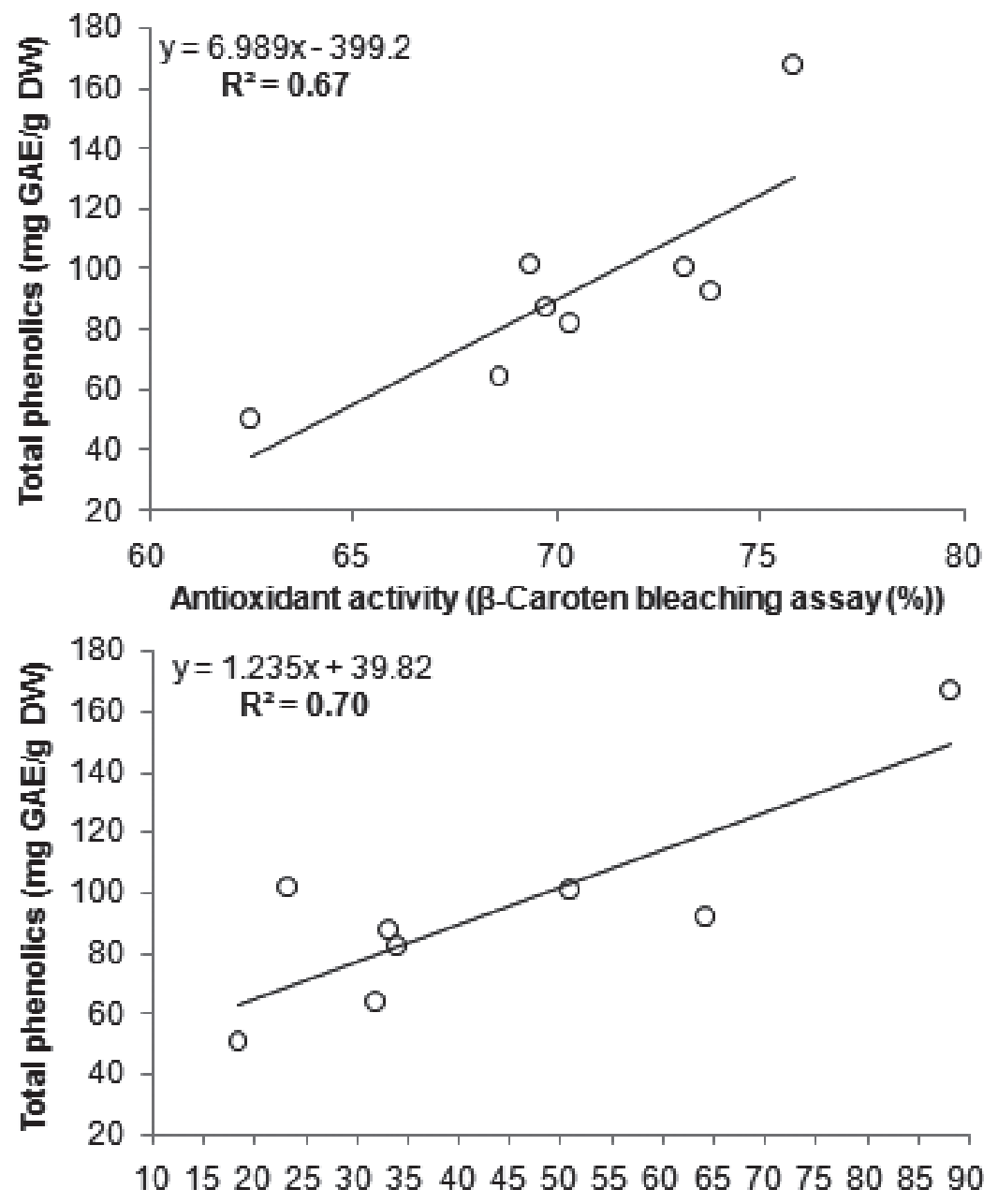

Antioxidant activity (DPPH 2,2-diphenylpicrylhydrazyl assay)

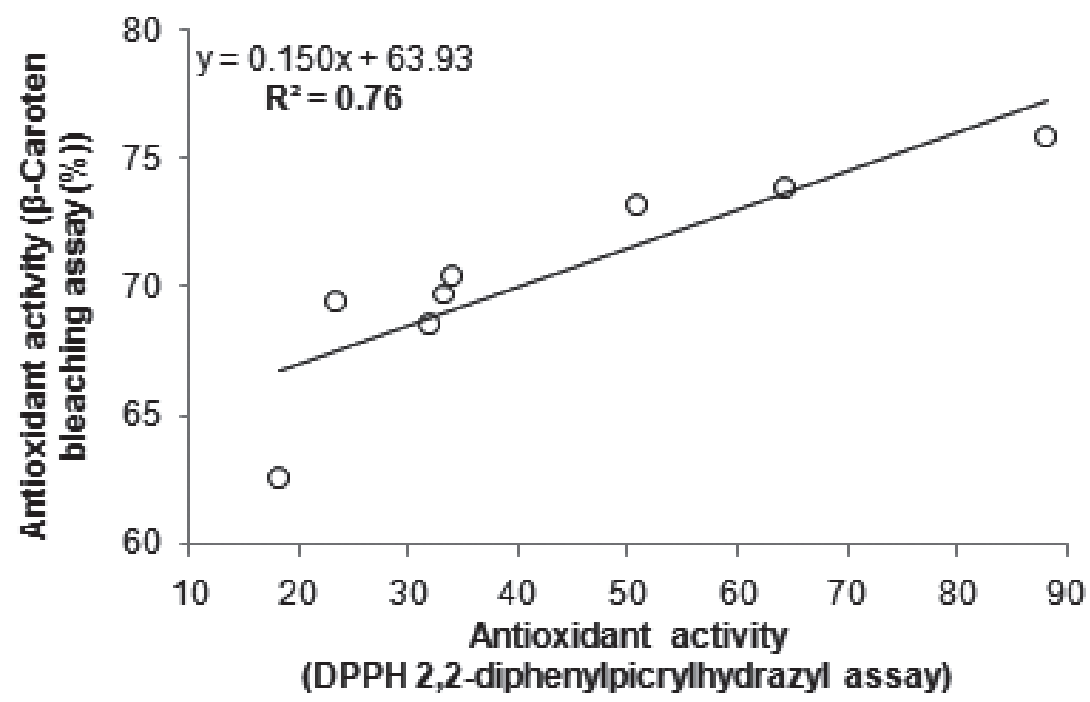

Figure 1: The ralationships between antioxidant activity and total phenolic content in eight Salvia species. 
phenolic content among Salvia species. It was well known that the occurrence of chemicals in aromatic and medicinal plants, in this case Salvia, is not only an indication of chemical diversity but may also help solve taxonomical problems. These chemicals have also attributed to have antioxidant activity. The antioxidant and chemical diversity is mostly illustrated with examples from genera such as Sideritis, Salvia, Thymus, Origanum, Satureja, Thymbra, Mentha, Micromeria, Ziziphora, Calamintha, Cyclotrichium, Acinos, Echinophora, Ferulago, Heracleum, Pimpinella, Tanacetum, and Betula. (31). Previously it was reported that $S$. aethiopis is rich in terms of oxygenated monoterpenes, $S$. candidissima and $S$. verticillata are rich in sesquiterpene hydrocarbons and S. microstegia is rich in oxygenated sesquiterpenes $(18,31)$. Therefore this difference is based on genetic derrivates of the species used. The phenolic and antioxidant diversity has been previously reported in many plants, such as persimmon (32), sea buckthorn (33) etc.

In conclusion, the methanolic extract of eight Salvia species exhibited different levels of antioxidant activity in all the models studied. The results from DPPH, free radical-scavenging system revealed that the Salvia had significant antioxidant and free radical-scavenging activity. The free radical-scavenging property may be one of the mechanisms by which these plants, notably Salvia verticillata and Salvia virgata, can be used as natural antioxidants.

\section{REFERENCES}

1. FINKEL $T$ (1998) Oxygen radicals and signaling. Current Opinion in Cell Biology 10: 248-253

2. HANCOCK J, DESIKAN R, NEILL S (2001) Role of reactive oxygen species in cell signaling pathways. Biochemical and Biomedical Aspects of Oxidase Modification 29: 345-350

3. HALLIWELL B, GUTTERIDGE J, CROSS C (1992) Free radicals, antioxidants, and human disease: How are we now? Journal of Laboratory and Clinical Medicine 119: 598-620

4. SASTRE J, PALLARDO FV, VINA J (2000) Mitochondrial oxidative stress plays a key role in aging and apoptosis. IUBMB Life, 49: 427-435

5. TAKABE W, NIKI E, UCHIDA $K$, YAMADA $S$,
SATOH K, NOGUCHI N (2001) Oxidative stress promotes the development of transformation: Involvement of a potent mutagenic lipid peroxidation product, acrolein. Carcinogenesis, 22: 935-941

6. KHAN MA, BASEER A (2000) Increased malondialdehyde levels in oronary heart disease. Journal of Pakistani Medical Association 50: 261-264

7. MORA A, PAYA M, RIOS JL, ALCARAZ MJ (1990) Structure-activity relationships of polymethoxyflavones and other flavonoids as inhibitors of non-enzymic lipid peroxidation. Biochemistry and Pharmacology 40: 793-797

8. CHEESMAN K, SLATER H (1993) An introduction to free radicals biochemistry. British Medical Bulletin 49: 481-493

9. CUVELIER ME, BERSET C, RICHARD H (1990) Use of a new test for determining cooperative antioxidative activity of butylated hydroxyanisole, butylated hydroxytoluene, alpha- and gamma-tocopherols and extracts from rosemary and sage. Sciences Des Aliments 10: 797-806

10. POKORNY J (1991) Natural antioxidants for food use. Trends in Food Science and Technology 9: 223-227

11. DAS NP, PEREIRA TA (1990) Effects of flavonoids on thermal autoxidation of palm oil: structure-activity relationships. Journal of the American Oil Chemists Society 67: 255-258

12. SCHWARZ K, TERNES W (1992) Antioxidative constituents of Rosmarinus officinalis and Salvia officinalis. II. Isolation of carnosic acid and formation of other phenolic diterpenes. Zeitschrift Fur Lebensmittel-Untersuchung Und-Forschung 195: 99103

13. GUNER A, OZHATAY N, EKIM T, BASER KHC (2000) Flora of Turkey and the East Aegean Islands (11). Edinburgh: Edinburgh University Press

14. CHALCHAT JC, MICHET A, PASQUIER B (1998) Study of clones of Salvia officinalis L. yields and chemical composition of essential oil. Flavour and Fragrance Journal 13: 68-70

15. SLINKARD K, SINGLETON VL (1997) Total phenol analyses: automation and comparison with manual methods. Am. J. Enol. Viticult. 28, 49-55

16. BURITS M, BUCAR F (2000) Antioxidant activity of Nigella sativa essential oil. Phytotherapy Research 14: 323-328

17. DAPKEVICIUS A, VENSKUTONIS R, BEEK TA, LINSSEN PH (1998) Antioxidant activity of extracts obtained by different isolation procedures from some aromatic herbs grown in Lithuania. Journal of the Science of Food and Agriculture 77: 140-146

18. KOSAR M, GOGER F, BASER KHC (2008) In vitro antioxidant properties and phenolic composition of Salvia virgata Jacq. From Turkey. J.Agric. Food Chem. 56: $2369-2374$

19. OGUTCU H, SOKMEN A, SOKMEN M, POLISSIOU M, SERKEDJIEVA J, DAFERERA D, SAHIN F, BARIS O, GULLUCE M (2008) Bioactivities of the various extracts and essential oils of Salvia limbata C.A. Mey. and Salvia sclarea L. Turkish Journal Biology 32: 181-192

20. TEPE B, SOKMEN M, AKPULAT HA, SOKMEN A (2006) Screening of the antioxidant potentials of six Salvia species from Turkey. Food Chemistry 95: 200204

21. UNAL EL, MAVI A, KARA AA, CAKIR A, SENGUL M, YILDIRIM A (2008) Antimicrobial and antioxidant activities of some plants used as remedies in Turkish traditional medicine. Pharmaceutical Biology 46: 207224 
22. NICKAVAR B, KAMALINEJAD M, IZADPANAH H (2007) In vitro free radical scavenging activity of five Salvia species. Pak. J. Pharm. Sci. 20: 291-294

23. SOARES JR, DINIS TC, CUNHUA AP, AMEIDA LM (1997) Antioxidant activities of some extracts of Thymus. Free Radical Research 26: 469-478

24. JAYAPRAKASHA GK, SINGH RP, SAKARIAH KK (2001) Antioxidant activity of grape seed (Vitis vinifera) extracts on peroxidation models in vitro. Food Chemistry 73: 285-290

25. HATANO T, EDAMATSU R, MORI A, FUJITA Y, YASUKARA T, YOSHIDA T (1989) Effects of the interaction of tannins with co-existing substances. VI. Effects of tannins and related polyphenols on superoxide anion radical and on 2,2'diphenylpicrylhydrazyl. Chemical and Pharmaceutical Bulletin 37: 2016-2021

26. LU Y, FO LY (2001) Salvianolic acid. A potent phenolic antioxidant from Salvia officinalis. Tetrahedron Letters 42: 8223-8225

27. MADSEN HL, BERTELSEN G (1995) Spices as antioxidant. Trends in Food Science and Technology 6: 271-277
28. WU JW, LEE MH, HO CT, CHANG SS (1982) Elucidation of the chemical structures of natural antioxidants isolated from rosemary. Journal of the American Oil Chemists Society 59: 339-345

29. WENG XC, WANG W (2000) Antioxidant activity of compounds isolated from Salvia plebeian. Food Chemistry 71: 489-493

30. DIPLOCK AT (1997) Will the good fairies please prove us that vitamin E lessens human degenerative disease? Free Radical Research 27: 511-532

31. BASER KHC (2002). Aromatic biodiversity among the flowering plant taxa of Turkey. Pure Appl. Chem., 4: 527-545

31. ERCISLI S, AKBULUT M, OZDEMIR O, SENGUL M, ORHAN E (2007). Phenolic and antioxidant diversity among persimmon (Diospyrus kaki L.) genotypes in Turkey'. Int. J. Food Sci. Nutrition, 59: 477-482

32. ERCISLI S, ORHAN E, OZDEMIR O, SENGUL M (2007). The genotypic effects on the chemical composition and antioxidant activity of sea buckthorn (Hippophae rhamnoides L.) berries grown in Turkey. Scientia Horticulturae, 115: 27-33. 
